\title{
Seroepidemiology of Plasmodium species infections in Zimbabwean population
}

\author{
Seth A. Amanfo ${ }^{1 *}$, Takafira Mduluza ${ }^{2,3}$, Nicholas Midzi ${ }^{4}$, David R. Cavanagh ${ }^{1}$ and Francisca Mutapi ${ }^{1}$
}

\begin{abstract}
Background: Individuals living in malaria-endemic regions may be exposed to more than one Plasmodium species; there is paucity of data on the distribution of the different species of Plasmodium in affected populations, in part due to the diagnostic method of microscopy, which cannot easily differentiate between the species. Sero-epidemiological data can overcome some of the shortcomings of microscopy.

Methods: The specificity of $\mathrm{lgG}$ antibodies to recombinant merozoite surface protein 1 (MSP-1 ${ }_{19}$ ) derived from four human Plasmodium species (Plasmodium falciparum, Plasmodium vivax, Plasmodium malariae, Plasmodium ovale) was investigated using competition enzyme-linked immunosorbent assay. Subsequently, these antigens were used to determine the exposure prevalence to the different Plasmodium species in serum samples of participants. One-hundred individuals, aged five-18 years, from each of the three Plasmodium meso-endemic Zimbabwean villages (Burma Valley, Mutoko, Chiredzi) were recruited in the study.
\end{abstract}

Results: The study demonstrated that the host serum reactivity to MSP-1 19 antigens was species-specific and that no cross-reactivity occurred. The overall prevalence of antibody response to MSP- $1_{19}$ antigens was $61 \%$ in Burma Valley, $31 \%$ in Mutoko and $32 \%$ in Chiredzi. Single species lgG responses to MSP-1 ${ }_{19}$ were most frequent against $P$. falciparum, followed by P. malariae and $P$. ovale, with responses to $P$. vivax being the least prevalent. Interestingly, $78-87$ and $50 \%$ of sera with $\operatorname{lgG}$ responses to $P$. malariae and $P$. ovale MSP-1 ${ }_{19}$, respectively, also had IgG specific response for $P$. falciparum MSP-1 19 antigens, indicating that exposure to these species is a common occurrence in these populations. Single species $\lg G$ responses to the non-falciparum species were at a very low frequency, ranging between 0 and $13 \%$ for P. malariae.

Conclusions: There is evidence of a higher exposure to the non-falciparum parasite species than previously reported in Zimbabwe. The recombinant MSP- $1_{19}$ antigens could be used as additional diagnostic tools in antibody assays for the detection of exposure to the different Plasmodium species. The results also introduce an interesting concept of the co-infection of non-falciparum Plasmodium almost always with P. falciparum, which requires further validation and mechanistic studies.

Keywords: Antibody, Merozoite surface protein $1\left(\mathrm{MSP}_{-1}{ }_{19}\right)$, Plasmodium, Microscopy

\section{Background}

Malaria is a major public health problem in sub-Saharan Africa, and is responsible for over half a million deaths annually, especially in children under the age of 5 years

\footnotetext{
*Correspondence: s.a.amanfo@sms.ed.ac.uk

${ }^{1}$ Institute of Immunology \& Infection Research and Centre for Immunity, Infection \& Evolution, Ashworth Laboratories, School of Biological Sciences, University of Edinburgh, King's Buildings, Charlotte Auerbach Rd, Edinburgh EH9 3FL, UK

Full list of author information is available at the end of the article
}

[1]. Four major species of the protozoan parasite, Plasmodium, (Plasmodium falciparum, Plasmodium vivax, Plasmodium malariae, Plasmodium ovale) cause human malaria in sub-Saharan Africa. In malaria-endemic countries, there is an overlap in the geographic distribution of the different Plasmodium species and the Anopheles mosquito vectors that transmit these parasites, and that individuals may be exposed to, and harbour multiple Plasmodium species [2]. However, the epidemiology of the different Plasmodium species in endemic human 
populations is not well documented [3]. Diagnosis of malaria in endemic clinical settings is predominantly by the 'gold standard' blood film microscopic examination, and rapid diagnostic tests (RDT), both of which lack sensitivity in differentiating the species of Plasmodium causing malaria. Microscopic examination has several limitations such as the inability to detect low levels of parasitaemia, and the difficulty in species differentiation owing to subtle differences in the morphology of blood stage parasites [4]. This results in the species of Plasmodium causing disease being rarely reported, and almost all cases of malaria are therefore attributed to P. falciparum, the species causing the most serious form of malaria [3]. This has led to underestimates of the prevalence of both mixed-species and non-falciparum species infections [5]. These non-falciparum species are of significant clinical importance; for example, $P$. vivax and $P$. ovale which form latent liver stage 'hypnozoites' are capable of causing disease several months or years after the primary infection [6]. Incidences of the diagnosis of systemic diseases caused by $P$. malariae several months or years after people have returned from malaria-endemic regions have been reported [7]. In some cases, drug treatment failure attributable to the misdiagnosis of primary infections caused by the non-falciparum species or as co-infecting species with P. falciparum have been observed [8]. While PCR typing of infecting Plasmodium species is not frequently available or applicable in many African field settings, most RDTs may not differentiate non-falciparum species [3]. There is an urgent need for additional diagnostic tools [2-4] capable of rapid detection of all four infecting Plasmodium species for effective treatment and control of malaria.

In this study, a new assay has been developed that detects exposure to all four human Plasmodium species based on serum antibody responses to merozoite surface protein 1 (MSP-1). The surface of the invasive merozoite is coated in MSP- 1 that constitutes $31 \%$ of the GPI-anchored proteins on P. falciparum merozoites [9]. MSP-1 is expressed by all four human Plasmodium species. In $P$. falciparum, MSP-1 undergoes two proteolytic cleavages resulting in a C-terminal MSP- $1_{19}$ fragment that is carried into the erythrocyte during merozoite invasion $[10,11]$. Until recently, only the MSP-1 genes of $P$. falciparum and P. vivax had been characterized. Recently, the sequences of the MSP- $1_{19}$ gene fragments for $P$. malariae and $P$. ovale have been determined with limited characterization of the responses to these parasite proteins [12]. Although the gene sequences of MSP$1_{19}$ antigens are unique to each of these four Plasmodium species, extensive homology can be found among them. The number and relative positions of cysteine residues within the C-terminus fragments of $\mathrm{MSP}^{-} 1_{19}$ are comparable in all four Plasmodium species [12]. For example, there are about 32 amino acid sites within the MSP- $1_{19}$ gene where all four parasite species share the same amino acid, and about 30 sites where the same amino acid is conserved in two or three species (Additional file 1: Figure S1). To date, there has been no field study using MSP- $1_{19}$ antigens from all four malaria parasite species to characterize the epidemiology of exposure to Plasmodium in any African population.

In Zimbabwe over half of the population are exposed to malaria, with $P$. falciparum being the predominant species, accounting for almost all cases of the disease [13]. There is little epidemiological data of exposure to nonfalciparum species and/or mixed Plasmodium infections in Zimbabwe. The aim of this study is to determine the species specificity of IgG antibody responses to recombinant Plasmodium MSP- $1_{19}$ antigens in three mesoendemic villages of Zimbabwe: Burma Valley, Mutoko and Chiredzi. Using these antigens as diagnostic tools, this study describes the sero-epidemiology of multiple Plasmodium species infections in these study sites.

\section{Methods}

\section{Study sites and population}

Serum samples were collected in three Zimbabwean villages where malaria parasite transmission is described as meso-endemic [13], as part of studies investigating the immuno-epidemiology of schistosomiasis in villages with Plasmodium co-infection. The study sites were Burma Valley in the northeast, where samples were collected in 1994, Chiredzi in the southeast where samples were collected in 1999 and Mutoko in central Zimbabwe, where samples were collected in 2003. The study cohort consisted of 100 participants aged between 5 and 18 years (both males and females) in each study site (Table 1). Antibody responses to merozoite surface proteins were detected using enzyme-linked immunosorbent assays (ELISA).

\section{Ethical approval and consent}

The studies in the different study sites received ethical approval from the Medical Research Council of Zimbabwe. Permission to conduct the work in each of the three

Table 1 Summary of study population

\begin{tabular}{|c|c|c|c|c|}
\hline \multirow[t]{2}{*}{ Study area } & \multirow{2}{*}{$\begin{array}{l}\text { Age range } \\
\text { (years) }\end{array}$} & \multirow{2}{*}{$\begin{array}{l}\text { Median age } \\
\text { (years) }\end{array}$} & \multicolumn{2}{|l|}{ Sex } \\
\hline & & & $\begin{array}{l}\text { Male } \\
(\%)\end{array}$ & $\begin{array}{l}\text { Female } \\
\text { (\%) }\end{array}$ \\
\hline Burma valley & $6-15$ & 10 & 49 & 51 \\
\hline Mutoko & $5-18$ & 9.5 & 36 & 64 \\
\hline Chiredzi & $7-16$ & 11 & 52 & 48 \\
\hline
\end{tabular}

100 individuals from each village were recruited into the study 
villages was obtained from the Provincial Medical Director, the District Educational Officer and Heads of schools in the study sites. Project aims and procedures were fully explained to the study participants and/or their guardian. Informed oral consent/assent was obtained from parents/ guardians, or participants if older than 10 years, prior to enrolment of the participants into the study. The participants were recruited into the study on a voluntary basis and were free to withdraw with no further obligation.

\section{Recombinant antigens}

MSP-1 antigens used in the ELISAs were expressed in Escherichia coli transformed with pGEX-derived plasmid constructs [14-17] as recombinant proteins fused to glutathione S-transferase (GST). These were purified by affinity chromatography using HiTrap glutathione Sepharose columns on an AKTAprime system and quantified by the Bradford protein assay.

\section{Serology}

Sera were tested by ELISA for the presence of IgG antibodies able to recognize the recombinant merozoite surface proteins as an indication of recent or current exposure; 96-well plates (Immulon4 HBX; Dynex, Greiner Microlon) were coated with $100 \mu \mathrm{L}$ of $0.5 \mu \mathrm{g} /$ $\mathrm{mL}$ of recombinant antigen in carbonate bicarbonate buffer (15 $\mathrm{mM} \mathrm{Na}_{2} \mathrm{CO}_{3}, 35 \mathrm{mM} \mathrm{NaHCO}$, $\left.\mathrm{pH} 9.4\right)$ and incubated overnight at $4{ }^{\circ} \mathrm{C}$ in a humidified atmosphere. Plates were washed four times in washing buffer $(0.05 \%$ Tween-20 in PBS) using Skatron Skanwasher to remove unbound antigens and blotted on paper towels (Kimberley Clark 3-ply hand towels Cat No. 6771). Free binding sites in wells were blocked with $200 \mu \mathrm{L}$ per well of blocking buffer $(1 \%(\mathrm{w} / \mathrm{v})$ skimmed milk powder in the PBS buffer) for $5 \mathrm{~h}$ at room temperature and then plates further washed four times. Human serum diluted 1:500 in the blocking buffer $(100 \mu \mathrm{L}$ per well) was added in duplicate to the Ag-coated wells and incubated overnight at $4{ }^{\circ} \mathrm{C}$. After four washes, the wells were incubated for $3 \mathrm{~h}$ at room temperature with $100 \mu \mathrm{L}$ per well of horseradish peroxidase-conjugated rabbit antihuman IgG (1:5000) (Dako Ltd, High Wycombe, UK). Plates were washed four times to remove unbound secondary antibody before reaction development with $100 \mu \mathrm{L}$ of substrate buffer $[(0.04 \mathrm{mg} / \mathrm{mL}$ of $o$-phenylenediamine; Sigma, St Louis, MO, USA; $0.012 \% \mathrm{H}_{2} \mathrm{O}_{2}$ in development buffer $(24.5 \mathrm{mM}$ citric acid monohydrate and $52 \mathrm{mM} \mathrm{Na}_{2} \mathrm{HPO} 4, \mathrm{pH}$ 5.0)] for 10-15 min at room temperature. An unstopped positive control plate was read at an optical density (OD) $450 \mathrm{~nm}$, with an OD $450 \mathrm{~nm}$ of $0.7-0.8$ taken to be equivalent to OD $492 \mathrm{~nm}$ of 2.5-3.0. The reaction was stopped by the addition of $25 \mu \mathrm{L}$ of $2 \mathrm{M} \mathrm{H}_{2} \mathrm{SO}_{4}$ per well, and OD was measured at $492 \mathrm{~nm}$ (Labsystems Multiskan Ascent microtitre plate reader). GST protein, purified from Escherichia coli transfected with pGEX-2T alone, was used as a control to determine the non-specific (background) binding of human IgG to the GST. Corrected OD values for each plasma sample were calculated by subtracting the mean OD value of wells containing control GST protein from the mean OD value obtained with each test MSP-1 antigen. Cut-off values at which binding of $\mathrm{Ab}$ from malaria-exposed individuals was regarded as significantly above background were calculated as corrected OD above the mean plus 4 standard deviation of OD readings obtained with sera from eight Scottish blood donors with no history of exposure to malaria. The same positive controls (pooled sera from Brefet, The Gambia) were run in duplicate, on each plate, to allow for standardization of plate-to-plate variations.

\section{Competition ELISA}

Competition ELISA was performed for individuals with substantial antibody reactivity to more than one MSP$1_{19}$ antigen, to assess whether human anti-MSP- $1_{19}$ IgG antibodies specific for MSP- $1_{19}$ were species-specific or cross-reacted with each other. Serum was pre-incubated with different concentrations of MSP- $1_{19}$ antigen, and then added to the wells of microtitre plates coated with either the homologous or heterologous MSP- $1_{19}$ antigen. The rationale of the competition ELISA is that appropriate antigen epitopes will react with their corresponding paratopes in the sera, so that with increasing antigen concentration, all paratopes in the sera react with the antigen, leaving none available to bind to antigen on the plate [18]. In the case of antigens without corresponding paratopes in the sera, there will be no prior reactivity between the serum and antigens, regardless of the antigen concentration. The same ELISA protocol above was followed with slight modification. Plates were coated with recombinant MSP- $1_{19}$ Ag and incubated overnight at $4{ }^{\circ} \mathrm{C}$. Serum was diluted (1:500) and pre-incubated with increasing concentrations $(0-10 \mu \mathrm{g} / \mathrm{mL})$ of soluble competing homologous or heterologous $\mathrm{Ag}$, i.e., with up to 20 -fold excess over the $0.50 \mu \mathrm{g} / \mathrm{mL}$ immobilized $\mathrm{Ag}$ to allow sera to bind to the antigen before reacting with the antigen bound on the plate, then tested on the platebound Ag overnight. This was followed by washing and incubation with a horseradish peroxidase-conjugated second $\mathrm{Ab}$, as described above.

\section{Statistical analyses}

To determine if exposure prevalence derived from single species data differed from that based on multiple species, Chi square $\left(x^{2}\right)$ tests were used. 


\section{Results}

Specificity of Plasmodium MSP-1 19 antigens

Competition ELISA showed that in sera reactive against recombinant MSP- $1_{19}$ antigens from more than one parasite species, anti-MSP- $1_{19}$ IgG antibody responses were species-specific and did not cross-react. As a positive control, when $P$. falciparum MSP- $1_{19}$ antigen was coated onto microtitre plates (as capture Ag), sera pre-incubated with $P$. falciparum MSP- $1_{19}$ (competing homologous $\mathrm{Ag}$ ), were inhibited from binding in a dose-dependent manner (Fig. 1). This inhibition occurred at competing homologous Ag concentration as low as $0.1 \mu \mathrm{g} / \mathrm{mL}$. Similar results were observed when the homologous competitor Ags were either $P$. malariae or $P$. ovale MSP- $1_{19}$. To assess anti-MSP- $1_{19}$ cross-reactivity, $P$. falciparum MSP- $1_{19}$ antigen was coated onto microtitre plates and dual specificity sera were pre-incubated with increasing concentrations of the heterologous P. malariae or P. ovale MSP- $1_{19}$ antigens. IgG binding to $P$. falciparum MSP- $1_{19}$ antigen was not inhibited by soluble heterologous $P$. malariae or $P$. ovale MSP- $1_{19}$, even at concentration 20 times the capture antigen. This was also true when the coating and competing antigens were reversed in the assay (Fig. 1).

\section{Prevalence of human IgG antibodies to recombinant MSP- ${ }_{19}$ antigens from four Plasmodium species}

Antibody recognition of the panel of four Plasmodium recombinant MSP- $1_{19}$ antigens was tested by ELISA against 100 sera from each of the three study sites (Burma Valley, Mutoko, Chiredzi). The observed overall prevalence of IgG response to all recombinant MSP- $1_{19}$ antigens was 61,31 and $32 \%$ in the Burma Valley, Mutoko and Chiredzi villages, respectively (Table 2). There were no significant differences between the exposure prevalence between the villages (Burma Valley vs Mutoko: $X^{2}=0.002, \mathrm{df}=1, P=0.97$ ), (Burma Valley vs Chiredzi: $\left.X^{2}=0.423, \mathrm{df}=1, P=0.52\right)$ and (Mutoko vs Chiredzi: $\left.X^{2}=0.001, \mathrm{df}=1, P=0.97\right)$

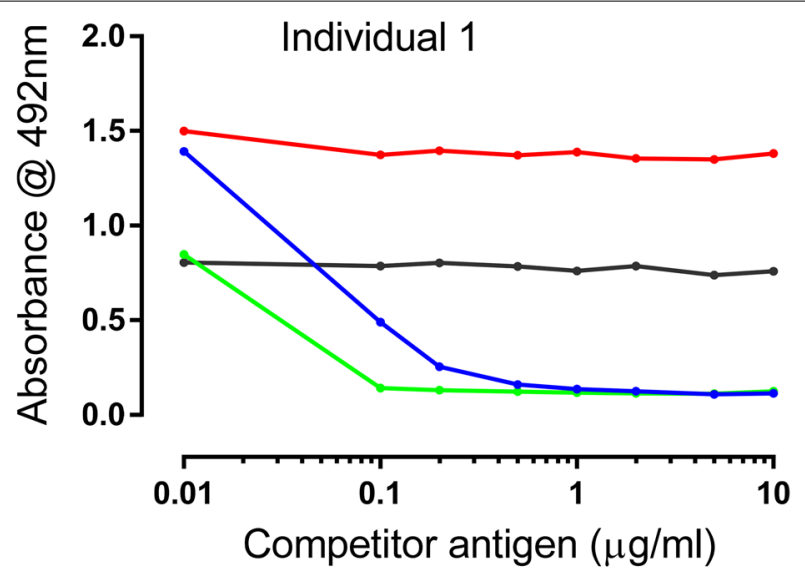

\section{Capture-competitor Ag pair \\ $\rightarrow$ falciparum-malariae \\ $\rightarrow$ falciparum-falciparum \\ $\rightarrow$ malariae-falciparum \\ $\because$ malariae-malariae}

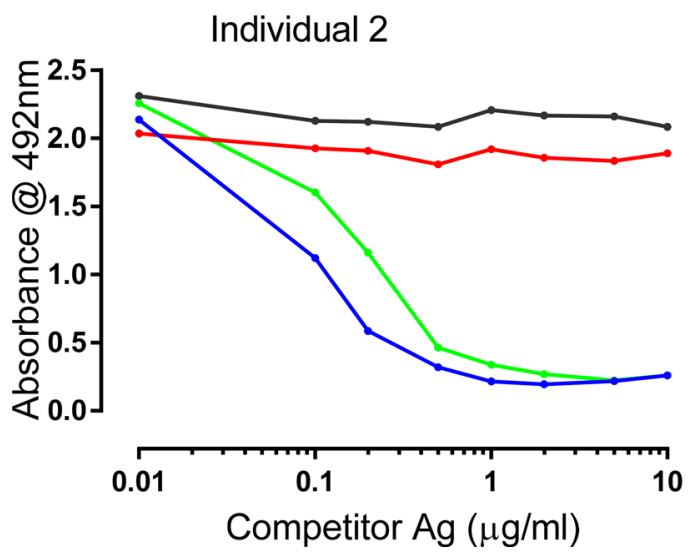

\section{Capture-competitor Ag pair}

$\rightarrow$ falciparum-ovale

$\rightarrow$ falciparum-falciparum

$\rightarrow$ ovale-falciparum

$\simeq$ ovale-ovale

Fig. 1 Competition ELISA showing species specificity of Abs to recombinant Plasmodium MSP- $1_{19}$ antigens for individuals 1 and 2 . Sera were tested at 1:500 dilution. Legends indicate the pairs of competing antigens used, with the well-bound capture antigen listed first and the competing homologous or heterologous antigen second. The capture antigens were coated at $50 \mathrm{ng} /$ well. The $x$-axis indicates increasing concentrations of competing antigen added to the diluted sera 


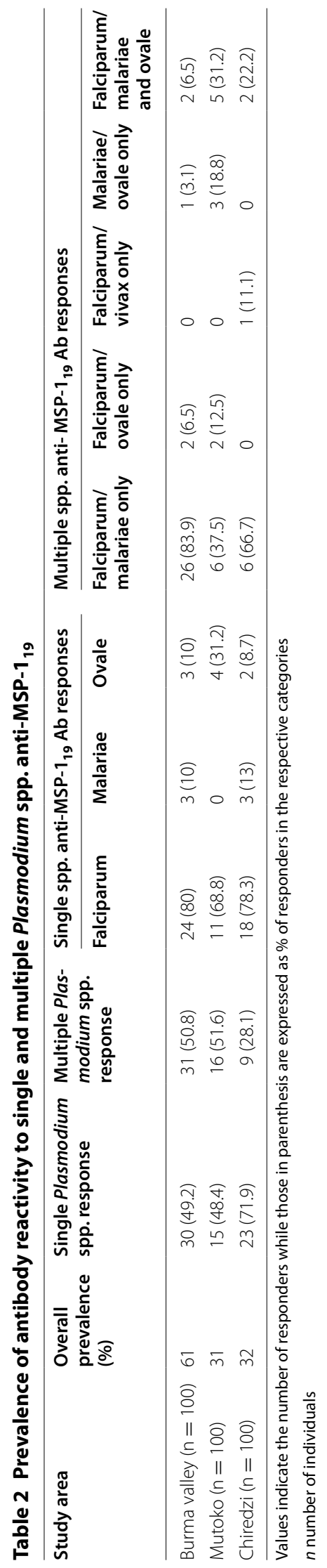




\section{Single vs multiple Plasmodium species anti-MSP-1 ${ }_{19}$ responses}

Of the individuals with anti-MSP- $1_{19}$ responses in all three study areas, Burma Valley $(\mathrm{n}=61)$, Mutoko $(\mathrm{n}=31)$ and Chiredzi $(\mathrm{n}=32)$, single species responses were the most common occurrence, and these were predominantly directed against $P$. falciparum MSP- $1_{19}$ antigens (80, 68.8 and $78.3 \%$, respectively), with responses to P. malariae or P. ovale ranging from 0 to $31.2 \%$ (Table 2). The proportion of individuals with single versus multiple species anti-MSP- $1_{19}$ responses in all three study villages were comparable.

In responders with antibodies to multiple Plasmodium species, antibody responses to the non-falciparum species were almost always accompanied by responses against $P$. falciparum MSP- $1_{19}$ antigens in all three study areas. Multiple responses to P. falciparum- and P. malariae MSP- $1_{19}$ were the most common, with about 78-87 and $50 \%$ of all sera with IgG responses to $P$. malariae and $P$. ovale MSP- $1_{19}$, respectively, also having IgG-specific response for $P$. falciparum MSP- $1_{19}$ antigens. The high exposure prevalence of IgG responses to $P$. malariae MSP- $1_{19}$ antigens suggests that infection with this parasite species is at a higher frequency in these populations than has been previously reported, and are predominantly co-responses to the main response to $P$. falciparum MSP-1 $1_{19}$ antigen.

While there were no single species responders to $P$. malariae MSP- $1_{19}$ in Mutoko, a much higher proportion $(31.2 \%)$ responded to three parasite antigens $(P$. malariae, $P$. falciparum, $P$. ovale) compared to the other two villages. Only one individual in Chiredzi had an antibody response to $P$. vivax antigen in addition to a response to $P$. falciparum (Table 2). When single species responses involving only $P$. falciparum was compared to multiple species responses involving $P$. falciparum with $P$. malariae and/or $P$. ovale, no significant difference was observed in all three villages (Fig. 2).

When the cohort was divided into two age groups, based on the median ages (i.e., those below 10 years and those 10 years and above), it was observed that the overall exposure prevalence in the two age groups were comparable in both Burma Valley $\left(\mathrm{x}^{2}=3.5, \mathrm{df}=1, P=0.06\right)$ and Mutoko $\left(\chi^{2}=0.05, \mathrm{df}=1, P=0.83\right)$. However, in Chiredzi a significantly higher exposure prevalence was observed in responders aged 10 years and above compared to those below 10 years $\left(x^{2}=6.13, \mathrm{df}=1\right.$, $P=0.01$ ) (Table 3). Differences between the two age groups in responders to single and multiple species in all three study areas were not compared because of the smaller sample sizes involved.

\section{Discussion}

In this current study, IgG responses to recombinant MSP- $1_{19}$ antigens (an indication of prior exposure to Plasmodium antigens) from the four major human Plasmodium species were evaluated in three Zimbabwean villages with meso-endemic malaria transmission dynamics. Individuals living in malaria-endemic regions may harbour multiple Plasmodium species owing to the

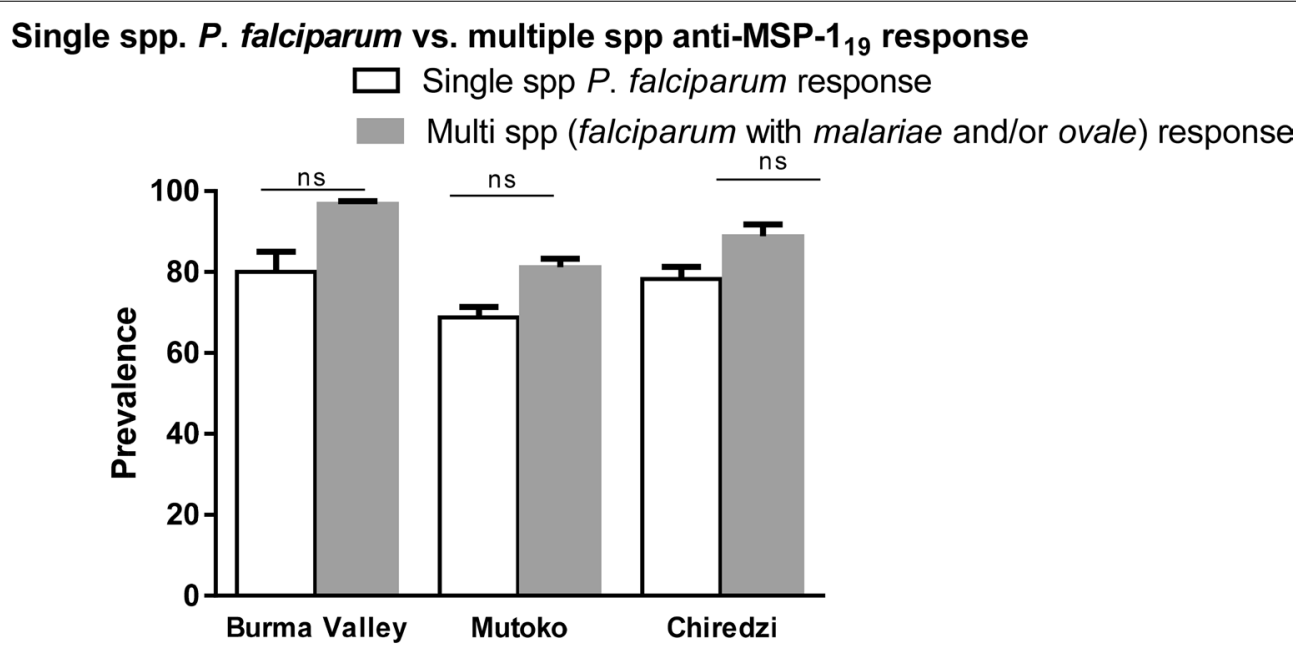

\section{Study districts}

Fig. 2 Prevalence of single Plasmodium falciparum vs multiple species anti-MSP- $1_{19}$ responses. Observed prevalence of single spp. P. falciparum anti-MSP- $1_{19}$ responses were compared with multiple responses involving $P$. falciparum with $P$. malariae and/or $P$. ovale in all three study sites 


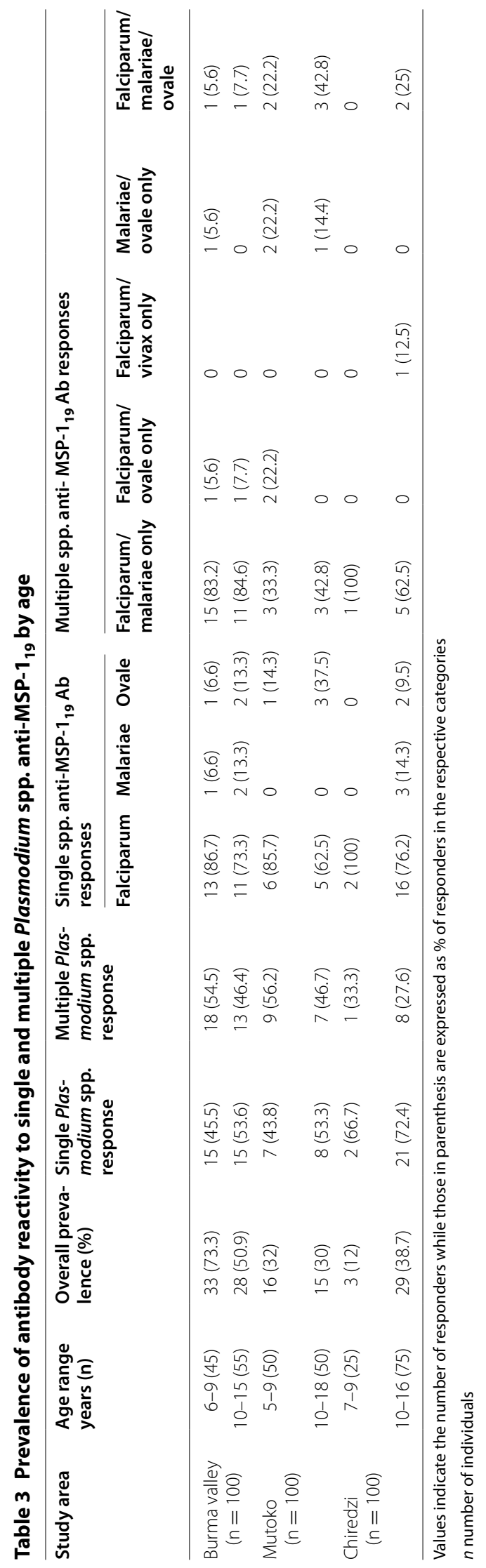


geographical overlap of the four major human Plasmodium species $[4,19,20]$. Malaria diagnosis in most African field settings is largely by microscopy of blood films, which reports the presence or absence of Plasmodium parasites without cognisance to the species causing disease. Low-level parasitaemia of the non-falciparum species in mixed infection with $P$. falciparum accounts for the misdiagnosis of these species. There have been case study reports of treatment failures [21] and acute renal injury [22] attributable to undiagnosed $P$. malariae infection or co-infection. Knowledge of the type of infecting species is therefore essential for effective treatment as well as the implementation of control programmes. IgG responses to $P$. falciparum MSP- $1_{19}$ antigens have been shown to rise following clinical episodes of malaria and decline in the absence of the disease [15]. In the current study, the antibody response to Plasmodium species recombinant MSP- $1_{19}$ antigens in humans was seen to be highly species-specific. Furthermore, the study showed that the responses were not cross-reactive, despite the amino acid sequence similarities between the four Plasmodium MSP- $1_{19}$ antigens. In experimental monkey and human studies utilizing all four Plasmodium species MSP- $1_{19}$ antigens, a superior sensitivity was seen when compared to commercially available antibody assays which only utilize MSP- $1_{19}$ antigens from $P$. falciparum and $P$. vivax and depend on cross-reactivity in detecting the other two species [23]. The specificity of antibodies to these antigens supports the evidence that these antigens could be used in pan-malaria diagnostic assay to enable the rapid detection of the type of Plasmodium species causing malaria [23].

In many malaria-endemic countries in sub-Saharan Africa, $P$. falciparum is the predominant species that causes malaria, thus it was not surprising that the antibody response to $P$. falciparum MSP- $1_{19}$ antigens was predominant in all three study sites. Since $P$. falciparum infections have higher parasitaemias than the other malaria parasite species $[20,24]$, it is likely that individuals will have a stronger immune response to $P$. falciparum infection. The novel results from this study were the indication that the exposure prevalence of $P$. malariae and $P$. ovale is higher, as previous reports have attributed about $98 \%$ of malaria in Zimbabwe to be caused by $P$. falciparum. More importantly, the observed higher exposure prevalence of $P$. malariae in the Burma Valley district was striking, as reports suggest that this species only accounts for between 1 and $2.6 \%$ of all malaria cases by light microscopy [25-27].

Microscopy has long been known to underestimate the prevalence of the non-falciparum species owing to difficulties in distinguishing the subtle differences in the morphology of the different species as well as the challenge posed in detecting minority species in a blood film with high density $P$. falciparum parasitaemia. It is therefore not surprising that these assays detected a higher sero-prevalence of these species, as this also reflects recent and concurrent parasite exposure. Studies employing nucleic acid based techniques for Plasmodium parasite detection and species identification in some African countries have reported prevalence of the nonfalciparum species to be between 1 and $17 \%[20,24]$.

While antibody responses to single species $P$. falciparum antigens were common, single species responses to $P$. malariae and $P$. ovale antigens were infrequently detected. A significant proportion of individuals with IgG responses to $P$. malariae and/or $P$. ovale MSP- $1_{19}$ almost always had responses to $P$. falciparum MSP- $1_{19}$. This results support the findings of a recent study in Ghana, which reported frequent detection of $P$. malariae and $P$. ovale in individuals who are also PCR positive for P. falciparum [28]. The reasons for this co-occurrence of the non-falciparum species with $P$. falciparum may be both epidemiological and biological. Of the epidemiological reasons, it has been suggested that the same Anopheles mosquito circulating in a population might be responsible for the simultaneous or sequential inoculation of the different species [4], thereby increasing the likelihood of multiple species infections. Biological reasons may include selective advantages for these minor species when co-infecting with $P$. falciparum. For example, due to density-dependent regulation of immune responses directed against the majority species (P. falciparum), these non-falciparum species may be able to evade host immune responses and establish disease $[29,30]$. There are parallels in other infectious diseases, such as the obligate satellite virus hepatitis $D$, which is unable to establish disease independent of hepatitis B virus [31]. Hepatitis D virus co-infection in Hepatitis B-infected individuals worsens hepatic damage and inflammation, and is more likely to lead to hepatocellular carcinoma [32,33]. The results show some single species $P$. malariae responses, indicating that this species is capable of establishing infection independent of other Plasmodium. However, the significant proportion of individuals with co-occurrence of antibody responses to $P$. falciparum suggests a possible dependency on $P$. falciparum receptors or proteins for successful disease by $P$. malariae. These non-falciparum species, which usually exist as part of a complex mixed-infections with $P$. falciparum [2, 34] may cause chronic, sub-clinical disease with potential health consequences, including treatment failure, disease relapse and long-term systemic consequences [5-7]. A recent 
study in Indonesia found $P$. malariae to be associated with a lower mean haemoglobin, nephrotic syndrome and death [27].

Antibody responses to $P$. vivax MSP- $1_{19}$ were rarely observed in this study. Plasmodium vivax requires the Duffy antigen to establish a successful infection [35], and is predominantly endemic in Asian and Latin American countries. It has long been known that the Duffy antigen is absent in most African populations [35]; it was therefore not surprising to observe a low frequency of responses to $P$. vivax MSP- $1_{19}$. In recent years however, there have been reports of $P$. vivax infections in both Duffy positive and negative individuals in Cameroon [36] suggesting that this species might have evolved and adapted to using other receptors to invade erythrocytes and establish disease.

Serological responses generally increase with age. In this present study, age was not a confounding factor in Burma Valley and Mutoko, while is Chiredzi responders 10 years old and above had a higher overall exposure prevalence to parasite antigens. Although all three villages are described as meso-endemic, the observed differences in age responses could be due to the respective transmission dynamics of the different seasons in which sampling was done. In very low and unstable malaria transmission areas such as Daraweesh in eastern Sudan, reports suggest that the age dynamics associated with malaria and serological responses are not apparent, as malaria affects all age groups $[37,38]$.

\section{Conclusions}

This study has shown for the first time that IgG antibodies to recombinant MSP- $1_{19}$ antigens of the four major human Plasmodium species are species-specific. The study also demonstrates that in Zimbabwean populations exposed to Plasmodium infections, the prevalence of the non-falciparum species responses is higher than previously reported in many other cross-sectional studies (reviewed in [3]). Finally, the study has demonstrated that a high proportion of individuals with antibody responses to non-falciparum MSP- $1_{19}$ antigens also had antibodies to $P$. falciparum MSP- $1_{19}$. MSP- $1_{19}$ antigens from all four major species of human malaria parasite offer a potential diagnostic tool for the rapid detection of exposure to multiple Plasmodium species such as in blood transfusion screening services. It remains to be established if these exposure responses to multiple Plasmodium species indicated by the serological survey correspond to concurrent or sequential exposure to previous or current infections.

\section{Additional file}

Additional file 1: Figure S1. Sequence homology of Plasmodium MSP$1_{19}$ antigens. Dots or semi-colons (. or :) indicate gene site where the same amino acid is shared between two or three Plasmodium species, while the stars $\left(^{*}\right)$ indicate conserved amino acid present in all four Plasmodium species.

\section{Abbreviations}

MSP: merozoite surface protein; RDT: rapid diagnostic test; PCR: polymerase chain reaction; ELISA: enzyme-linked immunosorbent assay; GST: glutathione S-transferase; OD: optical density.

\section{Authors' contributions}

FM, DRC and SAA conceived, designed and performed the experiments: FM, NM and TM participated in the fieldwork: FM, DRC, SAA, NM, and TM contributed to draft manuscript editing/reviewing. All authors contributed to the revisions. All authors read and approved the final manuscript.

\section{Author details}

${ }^{1}$ Institute of Immunology \& Infection Research and Centre for Immunity, Infection \& Evolution, Ashworth Laboratories, School of Biological Sciences, University of Edinburgh, King's Buildings, Charlotte Auerbach Rd, Edinburgh EH9 3FL, UK. ${ }^{2}$ Biochemistry Department, University of Zimbabwe, P.O. Box MP167, Mount Pleasant, Harare, Zimbabwe. ${ }^{3}$ School of Laboratory Medicine and Medical Sciences, University of KwaZulu Natal, Durban, South Africa. ${ }^{4}$ College of Health Sciences, Department of Medical, Microbiology, University of Zimbabwe, P.O. Box A178, Avondale, Harare, Zimbabwe.

\section{Acknowledgements}

We thank the study participants, as well as the parents/legal guardians, teachers, and residents of Burma Valley, Mutoko and Chiredzi in Zimbabwe for their kind support of this study. We are grateful to the Provincial Medical Director of Mashonaland East, Masvingo and Manicaland; nursing and technical staff in the Provincial hospitals. We are very grateful for the co-operation with the Ministry of Health and Child Welfare in Zimbabwe. For their technical support, we like to thank the National Institutes of Health Research Zimbabwe and members of the Department of Biochemistry at the University of Zimbabwe. Special thanks for reading and advice on the manuscript to members of the Parasite Immuno-epidemiology Group in Edinburgh. This work was supported by the MRC (UK), Wellcome Trust and the Darwin Trust of Edinburgh.

\section{Competing interests}

The authors declare that they have no competing interests.

Received: 10 March 2016 Accepted: 3 May 2016

Published online: 10 May 2016

\section{References}

1. WHO. World Malaria Report 2013. Geneva: World Health Organization; 2013.

2. Zimmerman PA, Mehlotra RK, Kasehagen LJ, Kazura JW. Why do we need to know more about mixed Plasmodium species infections in humans? Trends Parasitol. 2004;20:440-7.

3. Howes RE, Reiner RC Jr, Battle KE, Longbottom J, Mappin B, Ordanovich $D$, et al. Plasmodium vivax transmission in Africa. PLoS Neglect Trop Dis. 2015;9:e0004222.

4. Mueller I, Zimmerman PA, Reeder JC. Plasmodium malariae and Plasmodium ovale - the "bashful" malaria parasites. Trends Parasitol. 2007;23:278-83. 
5. Snounou G, White NJ. The co-existence of Plasmodium: sidelights from falciparum and vivax malaria in Thailand. Trends Parasitol. 2004;20:333-9.

6. Coldren RL, Jongsakul K, Vayakornvichit S, Noedl H, Fukudas MM. Apparent relapse of imported Plasmodium ovale malaria in a pregnant woman. Am J Trop Med Hyg. 2007;77:992-4.

7. Vinetz JM, Li J, McCutchan TF, Kaslow DC. Plasmodium malariae infection in an asymptomatic 74-year-old Greek woman with splenomegaly. N Engl J Med. 1998;338:367-71.

8. Smith A, Denholm J, Shortt J, Spelman D. Plasmodium species co-infection as a cause of treatment failure. Travel Med Infect Dis. 2011;9:306-9.

9. Gilson PR, Nebl T, Vukcevic D, Moritz RL, Sargeant T, Speed TP, et al. Identification and stoichiometry of glycosylphosphatidylinositol-anchored membrane proteins of the human malaria parasite Plasmodium falciparum. Mol Cell Proteom. 2006;5:1286-99.

10. McBride JS, Heidrich HG. Fragments of the polymorphic Mr 185,000 glycoprotein from the surface of isolated Plasmodium falciparum merozoites form an antigenic complex. Mol Biochem Parasitol. 1987;23:71-84.

11. Blackman MJ, Heidrich HG, Donachie S, McBride JS, Holder AA. A single fragment of a malaria merozoite surface protein remains on the parasite during red cell invasion and is the target of invasion-inhibiting antibodies. J Exp Med. 1990;172:379-82.

12. Birkenmeyer L, Muerhoff AS, Dawson GJ, Desai SM. Isolation and characterization of the MSP1 genes from Plasmodium malariae and Plasmodium ovale. Am J Trop Med Hyg. 2010;82:996-1003.

13. Taylor P, Mutambu SL. A review of the malaria situation in Zimbabwe with special reference to the period 1972-1981. Trans R Soc Trop Med Hyg. 1986;80:12-9.

14. Cavanagh DR, McBride JS. Antigenicity of recombinant proteins derived from Plasmodium falciparum merozoite surface protein 1. Mol Biochem Parasitol. 1997;85:197-211.

15. Cavanagh DR, Elhassan IM, Roper C, Robinson VJ, Giha H, Holder AA, et al. A longitudinal study of type-specific antibody responses to Plasmodium falciparum merozoite surface protein-1 in an area of unstable malaria in Sudan. J Immunol. 1998;161:347-59.

16. Burghaus PA, Holder AA. Expression of the 19-Kilodalton carboxy-terminal fragment of the Plasmodium falciparum merozoite surface protein-1 in Escherichia coli as a correctly folded protein. Mol Biochem Parasitol. 1994;64:165-9.

17. Polley SD, Conway DJ, Cavanagh DR, McBride JS, Lowe BS, Williams TN, et al. High levels of serum antibodies to merozoite surface protein 2 of Plasmodium falciparum are associated with reduced risk of clinical malaria in coastal Kenya. Vaccine. 2006;24:4233-46.

18. Gan SD, Patel KR. Enzyme immunoassay and enzyme-linked immunosorbent assay. J Invest Dermatol. 2013;133:e12.

19. Senn H, Alattas N, Boggild AK, Morris SK. Mixed-species Plasmodium falciparum and Plasmodium ovale malaria in a paediatric returned traveller. Malar J. 2014;13:78,

20. Bruce MC, Macheso A, Kelly-Hope LA, Nkhoma S, McConnachie A, Molyneux ME. Effect of transmission setting and mixed species infections on clinical measures of malaria in Malawi. PLoS ONE. 2008;3:e2775.

21. Savargaonkar D, Shah N, Das MK, Srivastava B, Valecha N. Plasmodium malariae infection: a case of missed diagnosis. J Vector Borne Dis. 2014:51:149-51.

22. Badiane AS, Diongue K, Diallo S, Ndongo AA, Diedhiou CK, Deme AB, et al. Acute kidney injury associated with Plasmodium malariae infection. Malar J. 2014;13:226.

23. Muerhoff AS, Birkenmeyer LG, Coffey R, Dille BJ, Barnwell JW, Collins $W E$, et al. Detection of Plasmodium falciparum, P. vivax, P. ovale, and $P$. malariae merozoite surface protein 1-p19 antibodies in human malaria patients and experimentally infected nonhuman primates. Clin Vaccine Immunol. 2010;17:1631-8.
24. Oguike MC, Betson M, Burke M, Nolder D, Stothard JR, Kleinschmidt I, et al. Plasmodium ovale curtisi and Plasmodium ovale wallikeri circulate simultaneously in African communities. Int J Parasitol. 2011;41:677-83.

25. Scopel KK, Fontes CJ, Nunes AC, Horta MF, Braga EM. Low sensitivity of nested PCR using Plasmodium DNA extracted from stained thick blood smears: an epidemiological retrospective study among subjects with low parasitaemia in an endemic area of the Brazilian Amazon region. Malar J. 2004;3:8.

26. Al-Maktari MT, Bassiouny HK. Malaria status in Al-Hodeidah Governorate, Republic of Yemen. Part II: human factors causing the persistence of chloroquine resistant $P$. falciparum local strain. J Egypt Soc Parasitol. 2003:33:829-39.

27. Langford S, Douglas NM, Lampah DA, Simpson JA, Kenangalem E, Sugiarto $\mathrm{P}$, et al. Plasmodium malariae infection associated with a high burden of anemia: a hospital-based surveillance study. PLoS Negl Trop Dis. 2015;9:e0004195.

28. Dinko B, Oguike MC, Larbi JA, Bousema T, Sutherland CJ. Persistent detection of Plasmodium falciparum, P. malariae, P. ovale curtisi and P. ovale wallikeri after ACT treatment of asymptomatic Ghanaian school-children. Int J Parasitol Drugs Drug Resist. 2013;3:45-50.

29. Bruce MC, Donnelly CA, Alpers MP, Galinski MR, Barnwell JW, Walliker D, et al. Cross-species interactions between malaria parasites in humans. Science. 2000;287:845-8.

30. Bruce MC, Day KP. Cross-species regulation of malaria parasitaemia in the human host. Curr Opin Microbiol. 2002;5:431-7.

31. Pascarella S, Negro F. Hepatitis D virus: an update. Liver Int. 2011;31:7-21.

32. Ho E, Deltenre P, Nkuize M, Delwaide J, Colle I, Michielsen P. Belgian Association for the study of the liver. Coinfection of hepatitis B and hepatitis delta virus in Belgium: a multicenter BASL study. Prospective epidemiology and comparison with HBV mono-infection. J Med Virol. 2013:85:1513-7.

33. Yurdaydin C, Idilman R, Bozkaya H, Bozdayi AM. Natural history and treatment of chronic delta hepatitis. JViral Hepat. 2010;17:749-56.

34. Kasehagen LJ, Mueller I, McNamara DT, Bockarie MJ, Kiniboro B, Rare L, et al. Changing patterns of Plasmodium blood-stage infections in the Wosera region of Papua New Guinea monitored by light microscopy and high throughput PCR diagnosis. Am J Trop Med Hyg. 2006;75:588-96.

35. Miller LH, Mason SJ, Clyde DF, McGinniss MH. The resistance factor to Plasmodium vivax in blacks. The Duffy-blood-group genotype, FyFy. N Engl J Med. 1976;295:302-4.

36. Fru-Cho J, Bumah VV, Safeukui I, Nkuo-Akenji T, Titanji VP, Haldar K. Molecular typing reveals substantial Plasmodium vivax infection in asymptomatic adults in a rural area of Cameroon. Malar J. 2014;13:170.

37. Giha HA, Theander TG, Staalso T, Roper C, Elhassan IM, Babiker H, et al. Seasonal variation in agglutination of Plasmodium falciparum-infected erythrocytes. Am J Trop Med Hyg. 1998;58:399-405.

38. Roper C, Elhassan IM, Hviid L, Giha H, Richardson W, Babiker H, et al. Detection of very low level Plasmodium falciparum infections using the nested polymerase chain reaction and a reassessment of the epidemiology of unstable malaria in Sudan. Am J Trop Med Hyg. 1996;54:325-31.

\section{Submit your next manuscript to BioMed Central and we will help you at every step:}

- We accept pre-submission inquiries

- Our selector tool helps you to find the most relevant journal

- We provide round the clock customer support

- Convenient online submission

- Thorough peer review

- Inclusion in PubMed and all major indexing services

- Maximum visibility for your research

Submit your manuscript at www.biomedcentral.com/submit
BioMed Central 